\title{
Erratum to: Performing China ON THE LONDON STAGE
}

\section{Ashely Thorpe}

The original version of the book contained errors which have been corrected. The corrections are given below:

\section{Chapter 1: Introduction: Mirrors of Empire}

Page 5, first and third line of Second paragraph 'Bhaba' has been changed to 'Bhabha'

Page 7, fifth and seventh line of first paragraph 'Bhaba' has been changed to 'Bhabha'

\section{Chapter 6: Seeking Subalterneity in S. I. Hsiung's Lady Precious} Stream, 1934

'Page 107, twentieth line 'Bhaba' has been changed to 'Bhabha'

\section{Chapter 8: Chinese Opera in the Diaspora from 1949}

Page 171, fifth line of third paragraph 'Bhaba' has been changed to 'Bhabha'

\section{Bibliography}

Page 237 twenty first line 'Bhaba' has been changed to 'Bhabha' Page 249 first line 'Bhaba' has been changed to 'Bhabha' 
E2 ERRATUM TO: PERFORMING CHINA ON THE LONDON STAGE

\section{Index}

Page 255 - fourteenth line 'Bhaba' has been changed to 'Bhabha'

The updated original online version for this book can be found at http://dx.doi.org/10.1057/978-1-137-59786-1 